\title{
Facilitators and barriers to employment for rural women cancer survivors
}

\author{
Emily Hallgren $^{1} \cdot$ Britni L. Ayers $^{1} \cdot$ Ramey Moore ${ }^{1} \cdot$ Rachel S. Purvis $^{1} \cdot$ Pearl A. McElfish ${ }^{1} \cdot$ Sanjay Maraboyina $^{2}$. \\ Gwendolyn Bryant-Smith ${ }^{3}$
}

Received: 10 December 2021 / Accepted: 1 February 2022

(c) The Author(s), under exclusive licence to Springer Science+Business Media, LLC, part of Springer Nature 2022

\begin{abstract}
Purpose Limited research exists on the employment experiences of rural women cancer survivors, yet this population may face unique barriers to employment following a cancer diagnosis. This study aims to identify facilitators and barriers to employment for rural women cancer survivors.

Methods We used a qualitative descriptive design to examine facilitators and barriers to employment for rural women cancer survivors. We conducted interviews with 33 rural women with cancer histories.

Results Facilitators of employment included paid time off, flexible work arrangements, and supportive workplace social networks, while barriers to employment included compromised immunity, long-term treatment effects, stigma and discrimination, and limited rural job markets. Rural women with secure employment histories generally experienced facilitators of employment, while rural women with insecure (e.g., temporary, informal, non-standard) employment histories generally faced barriers to retaining jobs and finding employment.

Conclusions Formal and informal workplace support helped rural women retain their jobs during and following cancer treatment, especially those with secure employment. However, women with insecure employment histories generally faced multiple barriers to retaining and finding employment. More inclusive policies to support workers facing disabling illnesses, such as paid medical leave, are needed to ensure cancer survivors can maintain employment and/or financial security during and following their cancer treatment.

Implications for Cancer Survivors Cancer survivors with secure employment may benefit from formal and informal workplace support in retaining their employment. Those with insecure employment histories may benefit from access to job placement services and inclusive policies protecting employment for all workers experiencing disabling illness.
\end{abstract}

Keywords Employment $\cdot$ Return to work $\cdot$ Cancer survivors $\cdot$ Rural $\cdot$ Qualitative

Emily Hallgren

ehallgren@uams.edu

1 College of Medicine, University of Arkansas for Medical Sciences Northwest, 1125 N. College Ave, Fayetteville, AR 72703, USA

2 Department of Radiation Oncology, University of Arkansas for Medical Sciences, 4301 W. Markham St., \#771, Little Rock, AR 72205, USA

3 Department of Radiology, University of Arkansas for Medical Sciences, 4301 W. Markham St. - Slot 556, Little Rock, AR 72205, USA

\section{Introduction}

Advancements in cancer detection and treatment have led to a growing cancer survivor population, with more than twothirds of cancer survivors living five years or longer after diagnosis [1]. In 2019, there were 17 million cancer survivors in the United States (US), representing five percent of the US population, and the number is projected to increase to 22.2 million by 2030 [1].

Employment provides important benefits for many cancer survivors including financial security, health insurance, a sense of identity, self-esteem, social support, and regaining a sense of normalcy [2-5]. Nearly half $(45 \%)$ of cancer survivors are working age (20-64) at the time of their diagnosis [6]. Systematic reviews estimated a work return 
rate of $62-64 \%$ for cancer survivors $[7,8]$, while a recent review estimated nearly three-quarters of long-term survivors ( $\geq 2$ years after diagnosis) return to work [9]. However, a survey found just $54 \%$ of working-age cancer survivors reported working full time [10]. Cancer survivors who lost employment due to cancer reported greater financial hardship and distress and were at higher risk of debt and bankruptcy compared to working survivors $[10,11]$.

Previous research found cancer survivors who had paid sick leave, accommodations such as flexible work arrangements, and higher income had higher work return rates than those without paid sick leave and workplace accommodations and those who had lower income [8, 12-18]. Further, survivors with workplace social support reported higher self-perceived work ability compared to those without social support at their workplace [19-21]. On the other hand, survivors whose work involved manual labor and heavy lifting and who perceived employer discrimination had lower return to work rates compared to those whose work did not involve manual labor or heavy lifting and those who did not perceive employer discrimination [7, 12, 22]. Regarding individual and cancer-related factors, survivors who were white, had higher education levels, had breast cancer, and took a shorter sick leave had higher work return rates compared to those who were racial/ethnic minorities, had less education, had a cancer other than breast, and took a longer sick leave [8, $13,18,22]$. In addition, survivors who were older, received chemotherapy, had head and neck cancer, and reported more physical limitations had worse work return rates than those who were younger, did not receive chemotherapy, had a cancer other than head and neck, and reported fewer physical limitations $[4,7,9,14,22]$.

Limited research suggests rural cancer survivors may have lower work return rates than urban survivors. Rural survivors are more likely than urban survivors to experience income loss, to retire early after their cancer diagnosis [23, 24], and to report health-related unemployment [25]. Rural cancer survivors may face unique barriers to employment given rural areas have a greater share of manufacturing jobs [26], which tend to be physically demanding, and lower job growth than urban areas [27]. Rural residents are generally older, have worse physical health, and have more comorbidities compared to urban residents $[25,28]$, which may exacerbate barriers to employment for rural cancer survivors.

Research suggests women cancer survivors have lower work return rates than men cancer survivors [8, 22]. Rural women cancer survivors may face particular barriers to employment given rural women earn lower wages than rural men [29], have less education, longer work commutes, and fewer transportation options than urban women [30, 31], and may lack the technological infrastructure to work from home [32]. No research, to our knowledge, has examined facilitators and barriers to employment retention or finding employment among rural women cancer survivors. The purpose of this study is to identify facilitators and barriers to employment for rural women cancer survivors.

\section{Methods}

\section{Study approach and design}

The authors used a qualitative descriptive design [33] to examine factors that helped or hindered participants in retaining employment and/or finding new work. All study materials and procedures were approved by the University of Illinois at Chicago Institutional Review Board (IRB\# 2016-0803) and the University of Illinois Cancer Center Protocol Review Committee.

\section{Recruitment, inclusion criteria, and remuneration}

Participants were recruited between November 2018 and June 2020 through three mechanisms:

1) Follow-up contact with participants of a survey, the Illinois Rural Cancer Assessment (IRCA) $(n=15)$

2) Study information shared with rural health care providers and community organizations $(n=16)$

3) Snowball recruitment $(n=2)$

Eligibility requirements were self-reported identification as a cancer survivor, self-identified reside nt of a rural area of Illinois, and being 18 years of age or older. All participants signed an informed consent and were provided a copy of the consent for their records. Each participant received $\$ 50$ for their time at the end of the interview.

\section{Sample description}

A total of 36 participants completed in-depth interviews during the study period. Of these participants, 33 reported that they were working at some point since their cancer diagnosis and are included in this study. Pseudonyms were assigned to all participants to protect confidentiality. Demographic, cancer, and employment characteristics for all participants are summarized overall and by employment history in Table 1 . Participants ranged in age from 36 to 76 , with an average age of about 57. Most participants had breast cancer $(n=25)$, and eight had other cancers. Twenty participants were married, and 13 were not married. The majority $(n=28)$ identified as White, and five identified as Black. Over half $(n=18)$ took paid time off, 13 did not take paid time off, and two were not working at the time of their diagnosis. Twenty-one survivors retained their jobs during cancer treatment, 10 left or lost their jobs, and two were not working at the time of their 
Table 1 Study sample characteristics

\begin{tabular}{|c|c|c|c|}
\hline \multirow[t]{2}{*}{ Demographic } & $\begin{array}{l}\text { Overall } \\
(n=33)\end{array}$ & $\begin{array}{l}\text { Secure employment } \\
\text { history } \\
(n=23)\end{array}$ & $\begin{array}{l}\text { Insecure } \\
\text { employment } \\
\text { history } \\
(n=10)\end{array}$ \\
\hline & $\begin{array}{l}\overline{\mathrm{x}}(\mathrm{SD}) \text { or } \\
n(\%)\end{array}$ & $\begin{array}{l}\overline{\mathrm{x}}(\mathrm{SD}) \text { or } \\
n(\%)\end{array}$ & $\begin{array}{l}\overline{\mathrm{x}}(\mathrm{SD}) \text { or } \\
n(\%)\end{array}$ \\
\hline Age & $56.70(11.08)$ & $57.61(12.28)$ & $54.60(7.82)$ \\
\hline \multicolumn{4}{|l|}{ Cancer type } \\
\hline Breast & $25(76 \%)$ & $17(74 \%)$ & $8(80 \%)$ \\
\hline Other & $8(24 \%)$ & $6(26 \%)$ & $2(20 \%)$ \\
\hline \multicolumn{4}{|l|}{ Marital status } \\
\hline Married & $20(61 \%)$ & $17(74 \%)$ & $3(30 \%)$ \\
\hline Not married & $13(39 \%)$ & $6(26 \%)$ & $7(70 \%)$ \\
\hline \multicolumn{4}{|l|}{ Racial group } \\
\hline White & $28(85 \%)$ & $21(91 \%)$ & $7(70 \%)$ \\
\hline Black & $5(15 \%)$ & $2(9 \%)$ & $3(30 \%)$ \\
\hline \multicolumn{4}{|l|}{ Took paid time off } \\
\hline Yes & $18(55 \%)$ & $15(65 \%)$ & $3(30 \%)$ \\
\hline No & $13(39 \%)$ & $8(35 \%)$ & $5(50 \%)$ \\
\hline Was not working at diagnosis & $2(0.6 \%)$ & 0 & $2(20 \%)$ \\
\hline \multicolumn{4}{|l|}{ Work outcome } \\
\hline Retained job & $21(63 \%)$ & $20(87 \%)$ & $1(10 \%)$ \\
\hline Left/lost job & $10(30 \%)$ & $3(13 \%)$ & $7(70 \%)$ \\
\hline Was not working at diagnosis & $2(0.6 \%)$ & 0 & $2(20 \%)$ \\
\hline \multicolumn{4}{|l|}{ Rurality } \\
\hline RUCC 1-3 (metropolitan) & $11(33 \%)$ & $11(48 \%)$ & 0 \\
\hline RUCC 4-9 (nonmetropolitan) & $22(67 \%)$ & $12(52 \%)$ & $10(100 \%)$ \\
\hline
\end{tabular}

diagnosis but later sought employment. Of the 33 participants, 22 lived in counties defined as nonmetropolitan (i.e., rural) by the Rural Urban Continuum Codes (RUCC), and 11 resided in counties defined by RUCC as metropolitan [34]. RUCC scores range from 1 to 9 , with 1 indicating the most metropolitan and 9 indicating the most nonmetropolitan. Scores 1-3 are considered metropolitan, and scores 4-9 are classified as nonmetropolitan. RUCC classifies entire counties as metropolitan/nonmetropolitan and, thus, may obscure variations in population density, urbanization, and distance to healthcare and other resources within counties [35]. Closer examination (by personal travel and Google Maps) revealed that participants residing in counties defined as metropolitan lived in exurban and rural areas outside of small and mid-sized cities.

\section{Data collection}

The majority of interviews $(n=26)$ were conducted in-person at a location of the participant's choosing (e.g., participant's home, local restaurant), six were conducted by phone, and one was conducted by video call. Interviews lasted one to three hours. All interviews were conducted in English and audio recorded. Survey questionnaires were completed just prior to interviews.

\section{Respondent questionnaire and interview guide}

The questionnaire covered demographic information, cancer-related employment experiences, and cancer-related financial hardship. The interview guide covered respondents' background, cancer history, cancer-related financial and employment experiences, experiences with caregivers, rural residency, and current physical and mental health. The interview guide was revised once during data collection to incorporate emergent themes including supportive workplace social networks, tangible support, and social support.

\section{Data analysis}

Interviews were transcribed verbatim by the first author or a professional transcription service. Transcripts were uploaded to MAXQDA 2020 and analyzed using a qualitative descriptive approach. In the first phase of coding, broad codes were developed based on key themes in the interview guide [36]. Initial codes were revised and refined through reflective memoing, comparing cases, and identifying patterns between transcripts. The umbrella themes of facilitators and barriers of employment were then 
developed, and code-theme fit was discussed among four qualitative researchers until inter-coder agreement was reached [33].

\section{Results}

\section{Secure vs. insecure employment}

Qualitative interview data revealed participants with secure employment generally experienced facilitators of job retention, while those with insecure (e.g., temporary, informal, non-standard) employment histories generally faced barriers to retaining jobs and finding new employment. While there were exceptions, this was a general trend among the sample.

Securely-employed participants generally had jobs that were full-time and offered some employment benefits (e.g., health insurance, paid time off), though they had a mix of salaried and hourly positions. While some secure positions were not high status or high paying, many participants had long job tenure, had close relationships with supervisors and co-workers, and described their workplaces as tight-knit. These formal and informal factors acted as job retention supports while women underwent cancer treatment and recovery.

Participants with insecure employment histories tended to work in temporary, informal, and non-standard work arrangements and often did not have employment benefits. While some had paid sick time, it was generally not adequate for their treatment and recovery needs. Their work more often involved manual and physically demanding tasks and close contact with the public and was generally low-paying. Given the insecure nature of their employment, most did not have long job tenure or strong personal relationships with supervisors or co-workers. Compared to the securely employed, these survivors did not have access to many formal or informal job retention supports. Meanwhile, characteristics of their jobs such as heavy lifting and close contact with the public, combined with a lack of workplace protections, accommodations, and support, resulted in physical barriers and health risks that were insurmountable for some survivors. Thus, cancer often ended what was already a tenuous employment relationship.

\section{Facilitators of employment}

Participants described multiple facilitators of employment. Facilitators included paid time off, flexible work arrangements, and supportive workplace social networks (Table 2).
Table 2 Facilitators and barriers to employment for rural women cancer survivors

\begin{tabular}{ll}
\hline Facilitators of employment & Barriers to employment \\
\hline - Paid time off & $\bullet$ Compromised immunity \\
- Flexible work arrangements & $\bullet$ Long-term treatment effects \\
- Supportive workplace social & • Stigma and discrimination \\
networks & $\bullet$ Limited rural job markets \\
\hline
\end{tabular}

\section{Paid time off}

Paid time off allowed participants to take relatively short periods of time away from work-generally six weeks or fewer-for treatment and recovery without relying on policies such as the Family Medical Leave Act (FMLA). Paid time off was generally a facilitator for those with secure employment. While some participants with insecure employment histories reported taking paid time off during cancer treatment, ultimately it did not facilitate job retention for most of them.

\section{Sick and vacation time}

Participants who retained their jobs generally used paid sick leave and vacation time to care for themselves and maintain full pay during their treatment and recovery. For some, long tenure at their jobs resulted in large banks of paid time off.

Julie: "Being here so long, they are nice enough to let it build up over time. I had so much sick time, there was a lot. They never take it away from you. I had seventeen years of sick time built up. So, I was really thankful because that way I could have my six weeks off for surgery paid."

Marie: "I took my vacation the last few [radiation] sessions, and then the week after I took off. So, I had a week to recover after before I had to go back to work. The last few sessions, it just emotionally, physically, everything, like a ton of bricks it just closed in on me."

\section{Not FMLA}

Most survivors who retained their employment relied solely on paid vacation and sick leave rather than FMLA. Jill noted, "I didn't use FMLA at all. No, because I had a pretty extensive sick time bank, so I had to use that up before I could use FMLA anyway." The few participants who took FMLA and retained their jobs specified they simultaneously used paid time off to maintain their full pay. Marilyn explained, "[I had] full pay. You can get family medical leave...But you're using your vacation and sick leave time to do it."

Notably, FMLA was considered a facilitator only by participants who lost their jobs during their cancer treatment. FMLA helped these participants retain their jobs longer, but they ultimately left or lost their positions. Nicole recalled, 
"It just kind of weaned down from being completely able to work full time hours to now I'm on FMLA. And now from FMLA I have to leave." Margaret noted, "I was on short term disability from when I [stopped working]. And then after I was gone for twelve weeks, then they told me that they posted my job."

\section{Flexible work arrangements}

Some participants described flexible work arrangements, including flexible schedule and flexible location, which allowed them to balance treatment and recuperation with work demands. With this flexibility, participants were able to endure the physical and mental effects of cancer treatment while continuing to work rather than pausing or leaving their jobs. Participants usually combined a flexible schedule with a flexible work location, which gave them the leeway to rest when they were feeling most sick or fatigued and resume work when they were able.

Jill: "I had my work laptop at home with me, and I could just work for, you know, an hour or so, rest, come back, maybe work on it for a while, rest. There were some days where I worked for an hour, there was some days where I could work three or four. And then when the chemo would wear off, I would actually come into the office."

Kari: "Post-surgery [bilateral mastectomy] you're just so tired to make it through. Just to make it a half day was beginning to get a struggle, and then you could go home and nap and rest, get your feet back under you again, and then you were able to try to keep up with everything by working from home."

\section{Supportive workplace social networks}

Several survivors described supportive networks of supervisors and co-workers who helped them retain their jobs. These supportive networks, often grounded in personal relationships and years of working together, functioned in a variety of ways to support cancer survivors' continued employment. Support from workplace social networks included instrumental and social support.

\section{Instrumental support}

Participants described instrumental (i.e., practical) support from supervisors and co-workers who helped them continue their jobs during cancer treatment and recovery. Some survivors were provided equipment, materials, and technology aids to help them continue working.

Kelly: "[My boss and an administrator] were delivering stuff. Both of them can easily go by my house, drop stuff off, pick stuff up. I've got a friend who works right next to me. She would do pick-ups and drop offs.
So it was a nice little routine. They hooked me up with so much stuff at home. It's sweet, and I'm very thankful and grateful for the group that I'm with, because not everybody can get that... We've got two guys who are more of the computer geeks that make the network happen for the company. So, the two guys came out, got me hooked up."

Brenda: "I couldn't talk loud enough for [my students] to hear me. I was literally almost whispering. And when you're lecturing, that doesn't work very well when you've got a group of about thirty students. So finally I said something to our AV department. I asked them, 'Do you have a portable microphone or something?' They said, 'No, but we can get you one.' ... They did get me that, and I used it for probably three months while I was still having trouble with my voice."

Other survivors received additional time off during treatment and recovery. Their supervisors disregarded official leave policies and granted them "off-the-books" time off (paid and unpaid). This accommodation allowed participants to take the time they needed for treatment and recovery and remain employed without relying on policies like FMLA.

Alice: "I had a week of personal time or sick time. And, I had a very, very compassionate boss. I got paid every week. And, I went to him at one point in time and said, 'I believe that you're not doing things the way it's set up.' He goes, 'You know what? You've worked here seventeen years. I think maybe we could afford to pay you.' So, they did and I didn't argue.” Patricia: "I told my boss at our Christmas Party, 'so I' $m$ released to come back because I just had the lumpectomy.' Well, then here I started chemo anyway. And he said, 'You can just stay off if you want to.' ...I was off seven months with the whole thing." Misty: "The administrator and I got along really well. Well, small town thing again. He was neighbors with my parents and brother. We kind of hit it off. Good relationship. Boss-employee relationship. He's the one that said, 'We'll keep your job. You know, you feel free. You need to rest. Get yourself better.' So he was basically the one that told me it'd be okay."

\section{Social support}

Workplace social networks also offered social support. Participants described how various forms of social support helped them remain at their jobs and feel supported at their workplace during and following cancer treatment.

Samantha: "So [my supervisor] told everybody on Friday morning, and I called a couple other co-workers, and so then they knew what time my surgery was. And they all went in that nutrition ed room and all said a prayer at 9 o'clock in the morning. And that's one 
[reason] why I'll never leave this place. Because they did so much for me."

Julie: "I have great co-workers. They were very kind, and they worked with me with a flexible schedule. So, I can't complain at all... I feel like sometimes I have chemo brain, so some of them were very nice to help fix some errors I had made or something like that." Ruby: "I had worked with these people so long, we were like a close-knit family. And so, they all embraced me, and I told [them] not to worry...Just pray for me...And then when I came back, there was a big clap and they were happy to see me back. They had sent me cards while I was sick. And they had a 'Welcome Back' sign. And just tried to do things to make me comfortable. If they were gonna go out and eat, 'You want me to bring you back something?' 'What are you gonna do for lunch?' Things like that."

\section{Barriers to employment}

Some survivors lost or left their jobs during cancer treatment and struggled to acquire new employment. Barriers to retaining and/or finding new work included compromised immunity, long-term treatment effects, stigma and discrimination, and limited rural job markets (Table 2).

\section{Compromised immunity}

Participants whose jobs involved close contact with people cited compromised immunity due to cancer treatment as a reason they left jobs or struggled to keep work. Notably, only participants with insecure employment histories experienced compromised immunity as an employment barrier. For survivors in secure jobs involving close contact with others, such as nurses and teachers, compromised immunity did not interfere with their ability to work.

Lisa: "I was babysitting at the time I found out I had cancer, so that's why I quit because when you babysit four kids and you're going through chemo treatments you don't know what [germs] they're going to bring home."

Beverly: "I worked for the school district. I did that a month...I was a supervisor for the lunch room. Got pneumonia so bad, I was sick for eight days. I almost had to be hospitalized. My doctor laughed. She said, 'you know where your immune system is at! Why did you take a job where there's all those sick little snottynosed kids? What were you thinking?' So, I asked them, 'can I wear gloves and a mask every day?' No, they really didn't want me to do that. So, I resigned. I had no choice. It was just like, well, thank you, but I can't continue here. This is gonna keep happening because my immune system, ever since the cancer, is low."

\section{Long-term treatment effects}

The long-term physical effects of cancer treatment made it difficult for some participants to retain their jobs or find new work. New physical limitations foreclosed employment options for some survivors, particularly those who worked in physically demanding jobs.

Carolyn: "[I have] multiple scars that go over my armpit and I won't ever be able to do a lot of heavy lifting or repetitive motion in my arm. I tried working at a factory for a while, and I can't do any repetitive motion. Plus my hands, it was smaller pieces that you're putting together. Because of my neuropathy and having a hard time with them, I just can't do all that kind of things...It's an economic punch in the head. You can't do everything you used to be able to do."

Cynthia: "After I got back and started working [as a crane operator], things changed so much, they added to the work that I needed to do. So I started doing that work with the regular job, and my hip fractured while I was working. That happened three months after I'd gone back. I haven't been able to go back since then... [The doctor] had me go into surgery immediately, and he put a rod in from my hip down to my knee. Then after that [the doctors] found out that I guess the chemotherapy and radiation had caused osteoporosis." Lisa: "I drove a taxi in town here for a bit, and I liked that. But I physically can't do the bending over anymore to buckle in the wheelchairs. I can't help the wheelchair accessible people. I can't do the stuff that I used to do...The chronic pain and the chronic fatigue syndrome, all that stuff is lasting effects that I've had because of cancer."

\section{Stigma and discrimination}

Some participants described stigmatization and discrimination, or anticipated discrimination, by prospective employers due to their cancer history. Survivors suspected that employers viewed their cancer history as a liability due to possible work limitations, the need for follow-up care, and the chance of recurrence.

Donna: "I went on several interviews, and I don't know if that's everywhere or just in this area, but the minute a prospective employer knew you had cancer, your interview went south...And I finally got to the point where I just quit saying anything. I feel [that for] a lot of employers here, you're a liability. You're a liability on their insurance, you're a liability on their time, 
you're a liability because they can't guarantee you can do the job."

Tonya: "When you fill out applications...they want to know your medical history. And if I tell somebody, well I'm dealing with cancer and treatments, and got to be off work. They don't want to hire nobody dealing with medical problems."

For some, the stigma of cancer was exacerbated by living in a small town where people often know each other's personal information.

Carolyn: "Sometimes I think I didn't get hired at a lot of jobs around here because there's a stigma now because everybody knows I was sick, I had cancer. I think sometimes a lot of people don't want to hire you because it could come back."

\section{Limited rural job markets}

Limited job opportunities in rural areas also served as an employment barrier for participants. This barrier interacted with the others to further limit survivors' opportunities for employment after cancer.

Melissa: 'I'm looking [for a job] like a crazy person. I've applied for several jobs, but I don't know... Unfortunately the market here is not the best. We thought about moving just to get to a bigger area. It's pretty depressed here right now economy wise. It just, there's just not a lot. The biggest employers are the hospitals." Nicole: "It's real hard to get jobs out here, I think... I applied, and I interviewed, and nobody hired me. But in [nearby city] they hired you like that [snapped fingers], but here no."

Margaret: "They told me I could transfer anywhere in [the hospital system]. Well, we're in the middle of nowhere. What jobs are going to be posted out here?"

\section{Discussion}

The purpose of this study was to identify facilitators and barriers to employment for rural women cancer survivors. Qualitative data revealed rural women with secure employment generally experienced facilitators of employment retention, while women with insecure employment histories generally experienced barriers to both retaining employment and finding new work. Facilitators of employment included paid time off, flexible work arrangements, and supportive workplace social networks. Notably, paid time off facilitated job retention, while FMLA was primarily used by women who ultimately left or lost their jobs. Barriers to employment included compromised immunity, long-term treatment effects, stigma and discrimination, and limited rural job markets.

Our findings regarding facilitators of employment align with previous research showing paid sick leave [14-16], flexible arrangements [37,38], and a flexible work schedule $[14,17]$ are associated with continued employment for cancer survivors. Sowden (2014) found fewer rural than urban survivors reported going on paid disability during their cancer [23]; this may indicate that rural cancer survivors have less access to paid leave. No previous research, to our knowledge, has identified flexible work location (i.e., ability to work from home) as a facilitator of employment for cancer survivors. Further, while previous international research has shown social support from colleagues and supervisors is associated with higher self-perceived work ability among employed survivors [19-21], our study is the first to identify supportive workplace social networks as a facilitator of continued employment for cancer survivors in the US.

The finding that compromised immunity was an employment barrier for rural women with insecure employment histories is novel in the literature. It is likely that securely employed survivors did not discuss compromised immunity as a barrier because they had more access to paid leave and employer accommodations to protect themselves while their immune systems were weak. Survivors with insecure jobs, on the other hand, had fewer workplace protections and accommodations to help safeguard their health. Compromised immunity has increased salience in the COVID19 era, and more research to understand the employment experiences of cancer survivors during the COVID-19 pandemic is needed. Our finding regarding the employment challenges posed by long-term treatment effects aligns with existing research showing that treatment-related effects are an employment barrier for cancer survivors, particularly the lasting effects of chemotherapy and extensive surgery [39, 40]. This helps explain why manual labor and physically demanding work are negatively correlated with work return among cancer survivors [12, 41]. Stigma and discrimination as employment barriers aligns with research showing cancer survivors worry about being stigmatized due to their illness and have experienced stigmatization and discrimination at the workplace and by prospective employers [42]. Further, limited rural job markets as a barrier is a novel finding. Notably, participants with insecure employment histories were much more likely to live in the most rural counties compared to those with secure employment (see Table 1). Previous research has primarily focused on demographic, cancer-related, and workplace-level correlates of employment for cancer survivors, with little attention to how broader economic and geographic context shapes access to employment. Future research should further explore the relationship between rurality, rural job markets, and employment for cancer survivors. 
Finally, participants generally did not discuss their marital status as a facilitator or barrier to employment, yet among the sample, there was a clear correlation between being married and retaining employment (see Table 1). Previous research found that being separated or divorced was associated with job and income loss among breast cancer survivors [24]. Further research should examine the relationship between marital or partnered status and employment outcomes for cancer survivors.

Limitations of this study include a non-random sample of women cancer survivors in rural Illinois and a cross-sectional study design. The small number of racial and ethnic minority women in the sample precluded analysis by race, although employment experiences very likely differ by racial group for cancer survivors in the rural US. Experiences of racism and discrimination may be missing from this analysis because it examines a predominantly white sample of rural women. The inclusion of women with secure and insecure employment histories and a range of job types is a strength of this study and responds to the call of a recent meta-review [4] to categorize survivors' employment experiences by work type (i.e., blue/white collar, casual, manual, professional work).

The insights from this study are important to informing health care policy, practice, and interventions. The US currently has two polices to protect employment for people diagnosed with disabling illnesses such as cancer: the Americans with Disabilities Act (ADA) and the FMLA $[43,44]$. However, these policies do not apply to temporary or informal workers or many small businesses, which may particularly affect rural cancer survivors. The participants in this study relied on paid time off, flexible work arrangements, and workplace social support to retain their employment more than federal policies intended to help individuals with disabling illnesses stay at their jobs. It is notable that FMLA was primarily used by survivors who ultimately lost their jobs during cancer treatment, suggesting that this policy is not always working as intended. These findings suggest the need for more inclusive policies, particularly paid medical leave for all workers. Access to job placement services is also needed for those who lost or had to leave their jobs during cancer treatment or other serious illnesses. European countries with more inclusive policies have demonstrated better work outcomes and financial stability for individuals with disabilities [45]. Notably, a meta-regression found the unemployment risk was 1.5 times higher for cancer survivors in the US compared to those in Europe [46]. The lack of more robust US policies leaves individual employees and employers with the responsibility of overlaying informal safety networks to help employees with serious illness sustain employment. This is concerning, as informal accommodations may not be equally applied, may be subject to the preferences and prejudices of individual employers, and are not subject to regulatory oversight. Further research is needed to identify additional facilitators and barriers to employment for rural cancer survivors and develop policies supportive of employment and financial security for cancer survivors.

Supplementary Information The online version contains supplementary material available at https://doi.org/10.1007/s11764-022-01179-y.

Author contribution All authors contributed to the study conception and design and/or the analysis and interpretation of data. Material preparation and data collection were done by Emily Hallgren. Data analysis and validation were performed by Emily Hallgren, Britni L. Ayers, Ramey Moore, Rachel S. Purvis, and Pearl A. McElfish. The first draft of the manuscript was written by Emily Hallgren and Britni L. Ayers. All authors critically reviewed manuscript drafts. All authors read and approved the final manuscript.

Funding This research was supported by graduate research awards from the Midwest Sociological Association, Sociologists for Women in Society, and the Provost Research Award at the University of Illinois at Chicago.

Data availability The deidentified data underlying the results presented in this study may be made available upon reasonable request from the corresponding author, Dr. Emily Hallgren, at ehallgren@uams.edu.

\section{Declarations}

Ethics approval All study materials and procedures were approved by the University of Illinois at Chicago Institutional Review Board (IRB\# 2016-0803) and the University of Illinois Cancer Center Protocol Review Committee.

Consent to participate All participants signed an informed consent and were provided a copy of the consent for their records.

Consent for publication The authors affirm that human research participants provided informed consent for publication of deidentified data.

Competing interests The authors declare no competing interests.

\section{References}

1. National Cancer Institute. Statistics, graphs and definitions. 2021. Available from: https://cancercontrol.cancer.gov/ocs/statistics. Accessed 30 Nov 2021.

2. Wells M, et al. Supporting 'work-related goals' rather than 'return to work'after cancer? A systematic review and meta-synthesis of 25 qualitative studies. Psychooncology. 2013;22(6):1208-19.

3. Rasmussen DM, Elverdam B. The meaning of work and working life after cancer: an interview study. Psychooncology. 2008;17(12):1232-8.

4. Butow P, et al. Return to work after a cancer diagnosis: a metareview of reviews and a meta-synthesis of recent qualitative studies. J Cancer Surviv. 2020;14(2):114-34.

5. Blinder VS, Gany FM. Impact of cancer on employment. J Clin Oncol. 2020;38(4):302.

6. Howlader N, et al. SEER cancer statistics review, 1975-2016. Bethesda: National Cancer Institute; 2019. 
7. Spelten ER, Sprangers MAG, Verbeek JHAM. Factors reported to influence the return to work of cancer survivors: a literature review. Psychooncology. 2002;11(2):124-31.

8. Mehnert A. Employment and work-related issues in cancer survivors. Crit Rev Oncol Hematol. 2011;77(2):109-30.

9. de Boer AG, et al. Long-term work retention after treatment for cancer: a systematic review and meta-analysis. J Cancer Surviv. 2020;14(2):135-50.

10. Banegas MP, et al. For working-age cancer survivors, medical debt and bankruptcy create financial hardships. Health Aff. 2016;35(1):54-61.

11. Blinder VS, et al. Five-year trajectories of financial recovery in low-income breast cancer survivors. J Clin Oncol. 2013;31(15 Suppl):9597.

12. Bouknight RR, Bradley CJ, Luo Z. Correlates of return to work for breast cancer survivors. J Clin Oncol. 2006;24(3):345-53.

13. Blinder $\mathrm{V}$, et al. Women with breast cancer who work for accommodating employers more likely to retain jobs after treatment. Health Aff. 2017;36(2):274-81.

14. Mujahid MS, et al. The impact of sociodemographic, treatment, and work support on missed work after breast cancer diagnosis. Breast Cancer Res Treat. 2010;119(1):213-20.

15. Veenstra CM, et al. Association of paid sick leave with job retention and financial burden among working patients with colorectal cancer. JAMA. 2015;314(24):2688-90.

16. Veenstra CM, et al. Employment benefits and job retention: evidence among patients with colorectal cancer. Cancer Med. 2018;7(3):736-45.

17. Kollerup A, et al. The importance of workplace accommodation for cancer survivors-the role of flexible work schedules and psychological help in returning to work. Econ Hum Biol. 2021;43:101057.

18. Nitecki R, et al. Employment outcomes among cancer patients in the United States. Cancer Epidemiol. 2022;76:102059.

19. Lindbohm M-L, et al. Work ability of survivors of breast, prostate, and testicular cancer in Nordic countries: a NOCWO study. J Cancer Surviv. 2012;6(1):72-81.

20. Carlsen K, et al. Self-reported work ability in long-term breast cancer survivors. A population-based questionnaire study in Denmark. Acta Oncol. 2013;52(2):423-9.

21. Musti MA, et al. Perceived work ability at return to work in women treated for breast cancer: a questionnaire-based study. Med Lav. 2018;109(6):407-19.

22. Van Muijen P, et al. Predictors of return to work and employment in cancer survivors: a systematic review. Eur J Cancer Care. 2013;22(2):144-60.

23. Sowden M, Vacek P, Geller BM. The impact of cancer diagnosis on employment: is there a difference between rural and urban populations? J Cancer Surviv. 2014;8(2):213-7.

24. Spencer JC, et al. Employment changes following breast cancer diagnosis: the effects of race and place. J Natl Cancer Inst. 2019;112(6):647-50.

25. Weaver KE, et al. Rural-urban disparities in health status among US cancer survivors. Cancer. 2013;119(5):1050-7.

26. United States Department of Agriculture. Rural manufacturing at a glance, 2017 edition. 2017. Available from: https://www.ers. usda.gov/webdocs/publications/84758/eib-177.pdf?v=4309.3. Accessed 30 Nov 2021.

27. United States Department of Agriculture. Rural employment and unemployment. 2019. Available from: https://www.ers.usda.gov/ topics/rural-economy-population/employment-education/ruralemployment-and-unemployment/. Accessed 30 Nov 2021.
28. Smith SA, Trevelyan E. The older population in rural America: 2012-2016. In: American Community Survey Reports. United States Census Bureau. 2019. Available from: https://www.census.gov/content/dam/Census/library/publications/2019/acs/acs41.pdf. Accessed 30 Nov 2021.

29. Robbins KG, Frye J, McGrew A. The gender wage gap among rural workers. 2018. Available from: https://www.americanpr ogress.org/article/gender-wage-gap-among-rural-workers/. Accessed 30 Nov 2021.

30. Smith KE, Tickamyer AR. Economic restructuring and family well-being in rural America. 1st ed. University Park: The Pennsylvania State University Press; 2013.

31. United States Department of Agriculture. Rural education at a glance, 2017 edition. 2017. Available from: https://www.ers. usda.gov/webdocs/publications/83078/eib-171.pdf?v=3725.9. Accessed 30 Nov 2021.

32. Vogels E. Some digital divides persist between rural, urban and suburban America. In: Rural Residents \& Tech. Pew Research Center; 2021. Available from: https://www.pewresearch.org/ fact-tank/2021/08/19/some-digital-divides-persist-between-ruralurban-and-suburban-america/. Accessed 30 Nov 2021.

33. Colorafi KJ, Evans B. Qualitative descriptive methods in health science research. HERD. 2016;9(4):16-25.

34. Taylor AK, et al. Getting rurality right: investigating cancer across the rural-urban interface. J Clin Oncol. 2020;38(15_suppl):e19063.

35. Salamon S. Newcomers to old towns: suburbanization of the heartland. 1st ed. Chicago: The University of Chicago Press; 2003.

36. Deterding NM, Waters MC. Flexible coding of in-depth interviews: a twenty-first-century approach. Sociol Methods Res. 2021;50(2):708-39.

37. Pryce J, Munir F, Haslam C. Cancer survivorship and work: symptoms, supervisor response, co-worker disclosure and work adjustment. J Occup Rehabil. 2007;17(1):83-92.

38. Alleaume $\mathrm{C}$, et al. The positive effect of workplace accommodations on the continued employment of cancer survivors five years after diagnosis. Support Care Cancer. 2020;28(9):4435-43.

39. Islam T, et al. Factors associated with return to work of breast cancer survivors: a systematic review. BMC Public Health. 2014;14(3):S8.

40. Johnsson A, et al. Work status and life changes in the first year after breast cancer diagnosis. Work. 2011;38:337-46.

41. Blinder VS, et al. Return to work in low-income Latina and nonLatina white breast cancer survivors: a 3-year longitudinal study. Cancer. 2012;118(6):1664-74.

42. Stergiou-Kita M, Pritlove C, Kirsh B. The "Big C"-stigma, cancer, and workplace discrimination. J Cancer Surviv. 2016;10:1035-50.

43. U.S. Equal Opportunity Employment Commission. The ADA: your employment rights as an individual with a disability. 2021. Available from: https://www.eeoc.gov/laws/guidance/your-emplo yment-rights-individual-disability. Accessed 30 Nov 2021.

44. Cancer and Careers. Your legal right in the workplace: cancer and the ADA, FMLA, etc. 2019. Available from: https://www.cance randcareers.org/en/at-work/legal-and-financial/cancer-and-theada-fmla. Accessed 30 Nov 2021.

45. Kaltenbrunner Bernitz B, et al. Young adults on disability benefits in 7 countries. Scand J Public Health. 2013;41(12 Suppl):3-26.

46. De Boer AG, et al. Cancer survivors and unemployment: a metaanalysis and meta-regression. JAMA. 2009;301(7):753-62.

Publisher's note Springer Nature remains neutral with regard to jurisdictional claims in published maps and institutional affiliations. 